\title{
Diffusion and $\gamma^{\prime}$ Phase Coarsening Kinetics in Ruthenium Containing Nickel Based Alloys
}

\author{
Efendi Mabruri ${ }^{1, * 1, * 2}$, Shingo Sakurai ${ }^{1, * 1}$, Yoshinori Murata ${ }^{1}$, \\ Toshiyuki Koyama ${ }^{2}$ and Masahiko Morinaga ${ }^{1}$ \\ ${ }^{1}$ Department of Materials, Physics and Energy Engineering, Graduate School of Engineering, \\ Nagoya University, Nagoya 464-8603, Japan \\ ${ }^{2}$ National Institutes for Materials Science, Tsukuba 305-0047, Japan
}

\begin{abstract}
The present paper reports the interdiffusion of $\mathrm{Re}, \mathrm{W}, \mathrm{Ru}$ and $\mathrm{Co}$ in the binary and pseudo-binary Ni based alloys at $1523 \mathrm{~K}$ and the $\gamma^{\prime}$ phase coarsening kinetics of model superalloys at $1324 \mathrm{~K}$. Both Re and $\mathrm{W}$ concentration gradients caused Ru uphill diffusion in the respective pseudo-binary diffusion couple, whereas Ru concentration gradient promoted uphill diffusion for W but not for Re. Interestingly, Re uphill diffusion occurred under the influence of Co concentration gradient but the reverse effect was not observed. The cross interdiffusion coefficients qualitatively determined from the uphill diffusion profiles were in reasonable agreement with those reported previously. Comparison of the interdiffusion coefficients in the binary and the pseudo-binary diffusion couples showed that Ru and $\mathrm{W}$ decreased the diffusivity of each other whereas Co appeared to be more powerful barrier atoms than Ru to decrease the Re diffusivity. Furthermore, it was evident that the coarsening kinetics of the $\gamma^{\prime}$ phase in both Ru-free and Ru-containing model superalloys were controlled by diffusion and Ru was found to have no effect on the rate constant of the $\gamma^{\prime}$ phase coarsening. [doi:10.2320/matertrans.MRA2007283]
\end{abstract}

(Received November 9, 2007; Accepted January 21, 2008; Published March 12, 2008)

Keywords: interdiffusion, rhenium, tungsten, ruthenium, cobalt, coarsening kinetics, nickel based superalloys

\section{Introduction}

Demands on higher efficiency and cleaner technology have been bringing out the need to raise the operating temperature of gas turbine system. As a consequence, the nickel based superalloys utilized in the gas turbine should meet this requirement by increasing their high temperature capability. The great progress in the increase of high temperature capability of these alloys is addressed by the incorporation of the refractory elements, especially $\mathrm{W}$ and Re. ${ }^{1-4)}$ These elements are enriched in the $\gamma$ matrix phase acting as the solid solution strengthener and making large the negative misfit between the matrix and the $\gamma^{\prime}$ precipitate. ${ }^{4-7)}$ It has been also reported that $\mathrm{Re}$ was the slowest diffusing element in $\mathrm{Ni}$ based superalloys ${ }^{8)}$ and reduced the coarsening rate of the $\gamma^{\prime}$ phase. ${ }^{7)}$ These alloying characteristics have a beneficial effect on the high temperature creep strength of the superalloys. Unfortunately, the amount of the refractory elements in Ni based superalloys is limited by the formation of TCP (topologically close packed) phases during high temperature exposure due to the microsegregation of these elements. ${ }^{4,9-11)}$ Recently, an increase in microstructural stability of the nickel based superalloys upon TCP phases formation has been achieved by the addition of $\mathrm{Ru}$, resulting in the enhancement of the creep strength. ${ }^{12,13)}$ Intensive researches are being conducted concerning the role of $\mathrm{Ru}$ as a new potent alloying element in the next generation of the single crystal nickel based superalloys. ${ }^{14-18)}$

The interdiffusion of refractory elements in $\mathrm{Ni}$ based superalloys is a field of interest since it is important in explaining the beneficial effect of these elements on high temperature processes. Some of the results regarding this topic in Ni based binary and some ternary systems have been

\footnotetext{
${ }^{* 1}$ Graduate Student, Nagoya University

${ }^{* 2}$ Corresponding author, E-mail: efendi@silky.numse.nagoya-u.ac.jp
}

reported in literature. ${ }^{7,18-22)}$ The present paper is addressed to the interdiffusion of Re, $\mathrm{W}$ and $\mathrm{Ru}$ in the pseudo-binary and the binary systems to investigate the effect of one solute to other solute in the system. As Co is also the element contributing to the improvement of the phase stability of the superalloys, the interdiffusion in the pseudo-binary system $\mathrm{Ni}-\mathrm{Co}-\mathrm{Re}$ is investigated and the result is compared to that in the pseudo-binary Ni-Ru-Re. Furthermore, the $\gamma^{\prime}$ phase coarsening experiment is performed on two model superalloys, one contains $\mathrm{Ru}$ and other contains no $\mathrm{Ru}$, in order to investigate the $\mathrm{Ru}$ effect on the kinetics of the $\gamma^{\prime}$ phase coarsening.

\section{Experimental Procedure}

The alloys made in this study were designed for the experiments on diffusion couples and on the $\gamma^{\prime}$ coarsening kinetics. Their compositions in $\mathrm{mol} \%$ are revealed in Tables 1 and 2, respectively. The button ingots of the alloys were prepared by arc melting in high purity argon gas atmosphere. For the diffusion couples, the ingots were annealed at $1523 \mathrm{~K}$ for $432 \mathrm{ks}$ so as to promote homogenization and grain growth. The alloys were cut into plateshape and ground flat and parallel. The plates were then polished with $0.25 \mu \mathrm{m}$ of diamond slurry in finishing and cleaned by acetone in an ultrasonic cleaner. The diffusion couples were assembled with two kinds of alloys of a system (Table 1) and, alumina fibers of several micrometers in diameter were placed between the polished surfaces of the plates as inert markers of initial interfaces. The couples were then clamped with molybdenum holders after the surfaces of the holders were coated by $0.3 \mu \mathrm{m}$ in diameter alumina powders to prevent direct contact with the alloys. The diffusion couples were encapsulated in quartz ampoules back filled with Ar gas and then annealed at the temperature for the given times presented in Table 1. After diffusion annealing 
Table 1 Composition (mol\%) of the diffusion couples for all systems and conditions of diffusion annealing employed in this study.

\begin{tabular}{llll}
\hline No & System & \multicolumn{1}{c}{ Diffusion Couple } & \multicolumn{1}{c}{$\begin{array}{c}\text { Diffusion } \\
\text { Annealing }\end{array}$} \\
\hline 1 & Ni-Ru-Re & $\begin{array}{l}\text { (a)Ni8Ru/Ni8Ru5Re } \\
\text { (b)Ni5Re/Ni8Ru5Re }\end{array}$ & $1523 \mathrm{~K}, 259.2 \mathrm{ks}$ \\
\hline 2 & $\mathrm{Ni}-\mathrm{Ru}-\mathrm{W}$ & $\begin{array}{l}\text { (a)Ni8Ru/Ni8Ru5W } \\
\text { (b)Ni5W/Ni8Ru5W }\end{array}$ & $1523 \mathrm{~K}, 259.2 \mathrm{ks}$ \\
\hline 3 & $\mathrm{Ni}-\mathrm{Co}-\mathrm{Re}$ & $\begin{array}{l}\text { (a)Ni5Co/Ni5Co5Re } \\
\text { (b)Ni5Re/Ni5Co5Re }\end{array}$ & $1523 \mathrm{~K}, 259.2 \mathrm{ks}$ \\
\hline 4 & $\mathrm{Ni}-\mathrm{Re}$ & $\mathrm{Ni} / \mathrm{Ni5Re}$ & $1523 \mathrm{~K}, 259.2 \mathrm{ks}$ \\
\hline 5 & $\mathrm{Ni}-\mathrm{W}$ & $\mathrm{Ni} / \mathrm{Ni5W}$ & $1523 \mathrm{~K}, 259.2 \mathrm{ks}$ \\
\hline 6 & $\mathrm{Ni}-\mathrm{Ru}$ & $\mathrm{Ni} / \mathrm{Ni} 8 \mathrm{Ru}$ & $1523 \mathrm{~K}, 259.2 \mathrm{ks}$ \\
\hline
\end{tabular}

Table 2 Composition (mol\%) of the model superalloys employed for $\gamma^{\prime}$ phase coarsening experiment.

\begin{tabular}{ccccccccc}
\hline Alloy & $\mathrm{Ni}$ & $\mathrm{Al}$ & $\mathrm{Cr}$ & $\mathrm{Co}$ & $\mathrm{Ta}$ & $\mathrm{W}$ & $\mathrm{Re}$ & $\mathrm{Ru}$ \\
\hline 1 & Bal. & 14.91 & 6.21 & 12.04 & 1.73 & 2.85 & 2.22 & 0 \\
\hline 2 & Bal. & 13.8 & 6.38 & 12.15 & 1.59 & 2.89 & 2.15 & 4 \\
\hline
\end{tabular}

proceeded for the given time, the ampoules were quenched by breaking them in water. Each diffusion couple was then sectioned perpendicular to the diffusion interface and polished to a $0.3 \mu \mathrm{m}$ finish and cleaned by acetone in an ultrasonic cleaner. The measurement of concentration of the elements across the diffusion interface was performed by an energy dispersive X-ray spectrometer (EDX) equipped with a scanning electron microscope (SEM).

For evaluation of the $\gamma^{\prime}$ phase coarsening kinetics the model superalloys as listed in Table 2 were homogenized and solutionized at $1587 \mathrm{~K}$ and then aged at $1324 \mathrm{~K}$ for the duration of 5, 24, 72, 160 and $256 \mathrm{~h}$. The aged alloys were treated by standard metallographic procedure for microstructure examination with SEM. The mixed solution of $\mathrm{HCl}+\mathrm{HNO} 3$ in same portion was used for etching to reveal the microstructures. The $\gamma^{\prime}$ sizes were measured on SEM photos by using the image analyzer software. ${ }^{23)}$ The lengths of $\gamma^{\prime}$ cube-edges in two directions were measured for about 200 precipitates in each alloy for each aging condition.

\section{Results and Discussion}

\subsection{Interdiffusion of Re, W, Ru and Co in binary and pseudo-binary alloys}

The diffusion couple consisting three elements such as $\mathrm{Ni8Ru/Ni8Ru5Re}$ is designed for the pseudo-binary system to provide only one concentration gradient of the solute to contribute to the diffusion fluxes such that $\mathrm{Ru}$ is kept in constant concentration whereas $\mathrm{Re}$ is allowed to have a concentration gradient. From such a kind of diffusion couple system, it can be extracted two facts; firstly the effect of $\mathrm{Ru}$ addition on the interdiffusion rate of Re can be evaluated by taking the comparison between the rates in the pseudo-binary $\mathrm{Ni}-\mathrm{Ru}-\mathrm{Re}$ and in the binary Ni-Re. Secondly, the effect of Re concentration gradient on $\mathrm{Ru}$ can be evaluated by observing the concentration profile of Ru which was initially a constant.
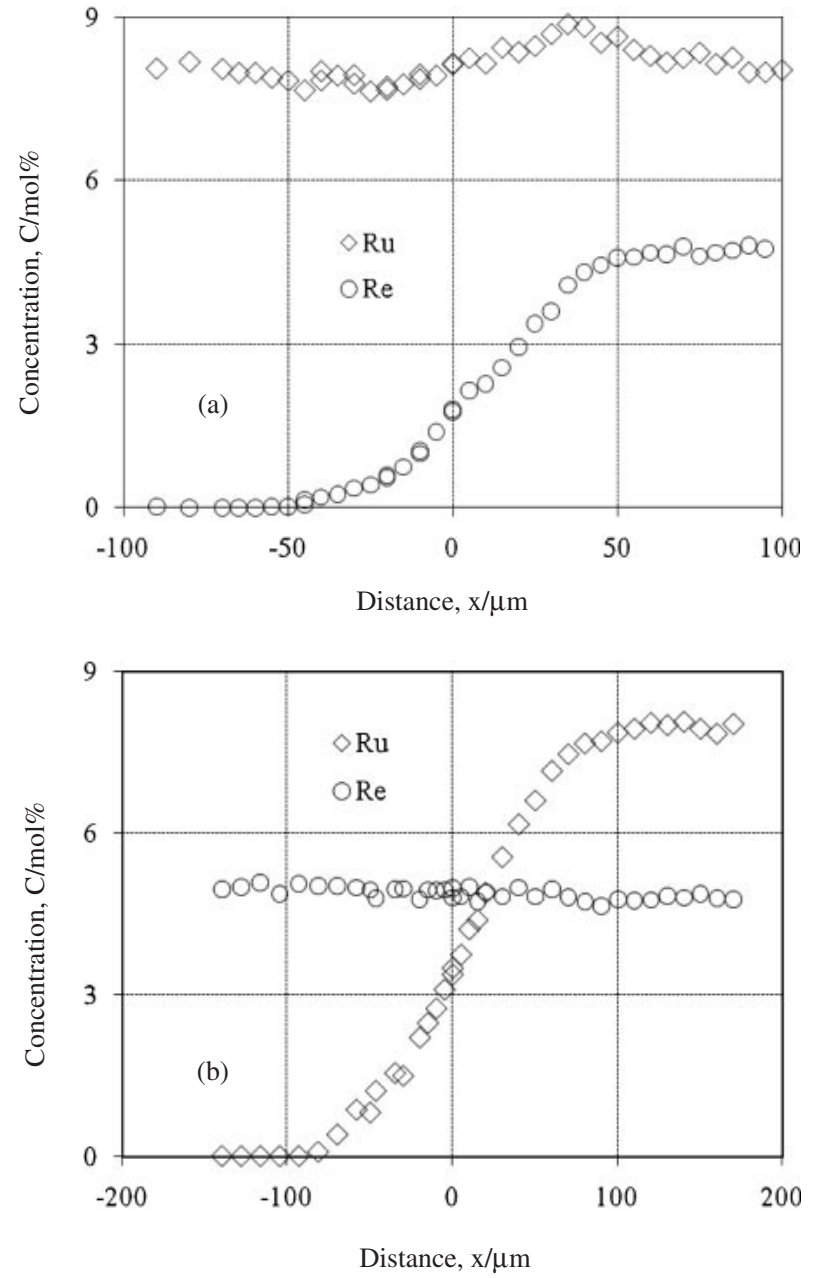

Fig. 1 The redistribution profiles of $\mathrm{Ru}$ and $\mathrm{Re}$ in (a) Ni8Ru/Ni8Ru5Re and (b) Ni5Re/Ni8Ru5Re diffusion couples after diffusion annealing at $1523 \mathrm{~K}$ for $259.2 \mathrm{ks}$.

For example, interdiffusion flux in a ternary system is expressed by Generalized Ficks First Law as follows:

$$
\tilde{J}_{i}=-\tilde{D}_{i i}^{k} \frac{\partial C_{i}}{\partial x}-\tilde{D}_{i j}^{k} \frac{\partial C_{j}}{\partial x},
$$

where $\tilde{D}_{i i}^{k}$ is the major interdiffusion coefficient, $\tilde{D}_{i j}^{k}$ is the cross interdiffusion coefficient. Here, we consider $i, j, k$ as $\mathrm{Ru}, \mathrm{Re}$ and $\mathrm{Ni}$, respectively. If $\mathrm{Ru}$ concentration is a constant, then $\frac{\partial C_{i}}{\partial x}$ in eq. (1) is equal to zero. As a result, the effect of $\mathrm{Re}$ concentration gradient $\left(\frac{\partial C_{j}}{\partial x}\right)$ appears directly to $\mathrm{Ru}$ interdiffusion flux $\left(\tilde{J}_{i}\right)$. The similar meaning holds for the other diffusion couples containing three elements made in this study.

Figures 1 and 2 present the measured redistribution profiles for the solute elements in the diffusion couples for the Ni-Ru-Re and Ni-Ru-W pseudo-binary systems, respectively. Each figure displays two types of redistribution profiles. The S-shape profile belongs to the main diffusing element and the roughly constant profile belongs to the element having an initially constant concentration. However, by observation on the enlarged views as shown in Figs. 3 and 4 , it is clear that most of the roughly constant profiles demonstrate the phenomena called uphill diffusion. In particular, it is shown that the uphill diffusion of $\mathrm{Ru}$ occurs 

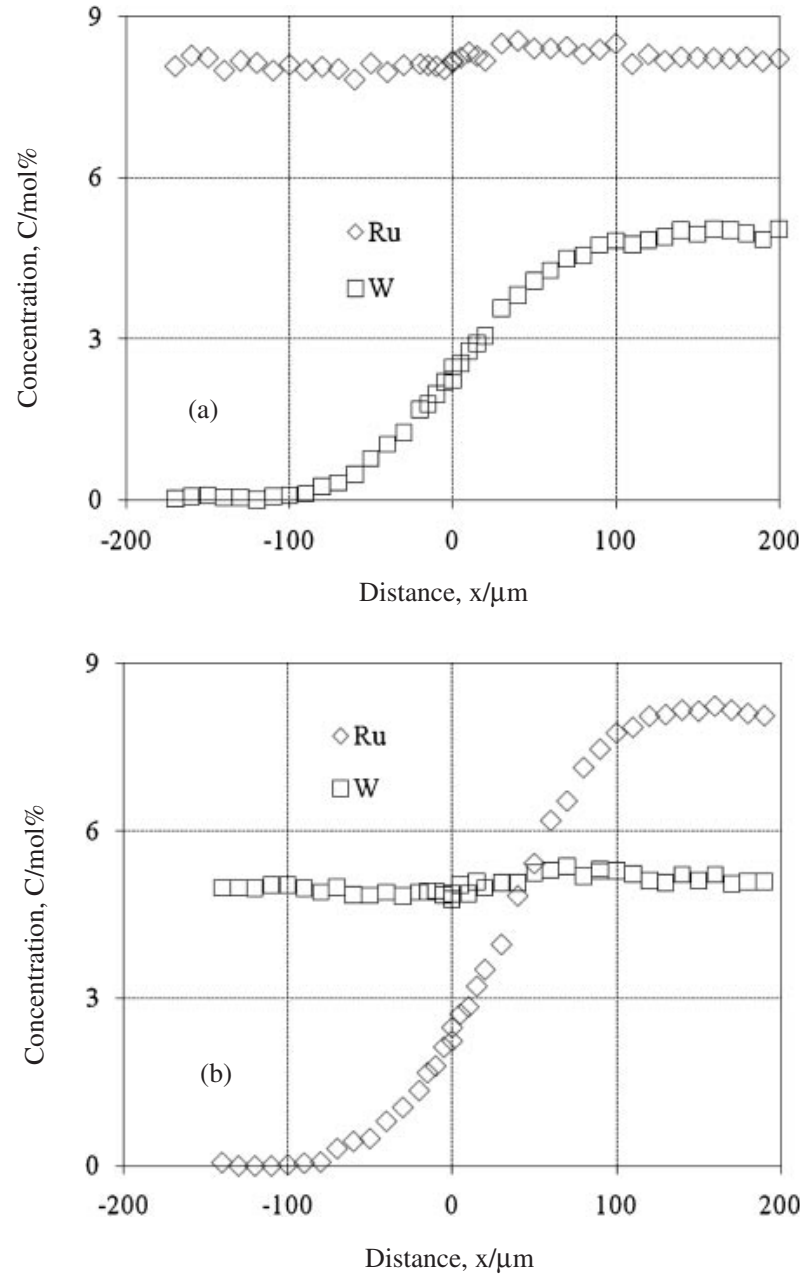

Fig. 2 The redistribution profiles of Ru and $\mathrm{W}$ in (a) Ni8Ru/Ni8Ru5W and (b) Ni5W/Ni8Ru5W diffusion couples after diffusion annealing at $1523 \mathrm{~K}$ for $259.2 \mathrm{ks}$.

in both pseudo-binary diffusion couples of $\mathrm{Ni8Ru} / \mathrm{Ni} 8 \mathrm{Ru} 5 \mathrm{Re}$ and Ni8Ru/Ni8Ru5W, respectively in Fig. 3(a) and (b). The degree of uphill diffusion of $\mathrm{Ru}$ is larger in $\mathrm{Ni}-\mathrm{Ru}$-Re system than in Ni-Ru-W system, as can be observed by larger difference in maximum and minimum concentrations of $\mathrm{Ru}$ in Ni-Ru-Re system. This fact indicates that Re has stronger effect than $\mathrm{W}$ on the change of the Ru chemical potential as the driving force for the uphill diffusion. As for the effect of $\mathrm{Ru}$ on both $\mathrm{Re}$ and $\mathrm{W}$ fluxes, different behavior is observed between $\mathrm{Re}$ and $\mathrm{W}$ in the respective system, as shown in Fig. 4(a) and (b), i.e. clear uphill diffusion is not observed for $\mathrm{Re}$, where it is observed for W. It indicates that Ru changes the chemical potential of $\mathrm{W}$ but scarcely changes that of Re.

The enlarged view of the redistribution profiles of the initially constant concentration elements in the pseudobinary diffusion couples of Ni-Co-Re system after annealing at 1523 for $259.2 \mathrm{ks}$ is displayed in Fig. 5(a) and (b). It is interesting to note that the uphill diffusion is clearly observed on the redistribution profile of Re under the influence of Co concentration gradient in the diffusion couple of $\mathrm{Ni5Re} /$ Ni5Co5Re, as shown in Fig. 5(a). In contrast, Re concentration gradient appears not to promote the uphill diffusion of $\mathrm{Co}$ in the diffusion couple of $\mathrm{Ni5Co} / \mathrm{Ni5Co5Re}$ as illustrated in Fig. 5(b). It implies that the chemical potential of $\mathrm{Re}$ is
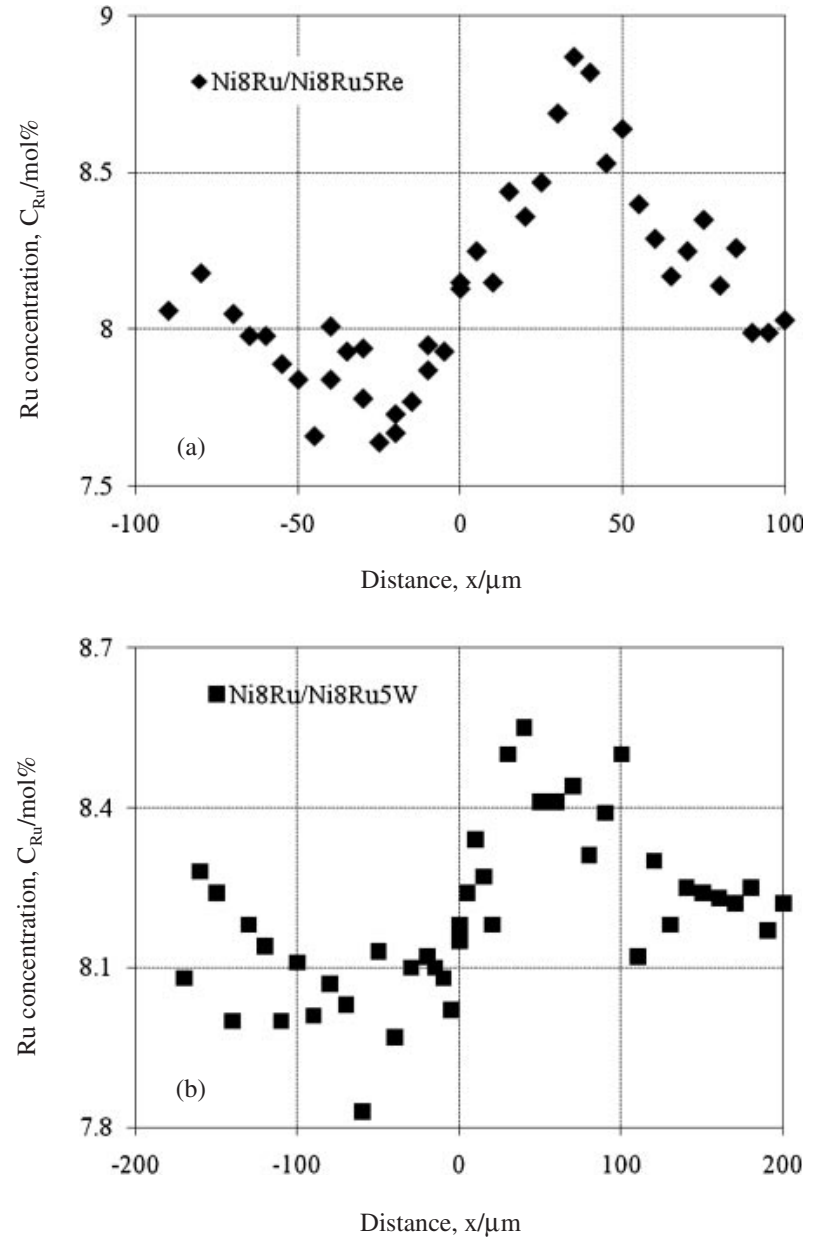

Fig. 3 Enlarged views of the redistribution profiles of $\mathrm{Ru}$ in (a) $\mathrm{Ni} 8 \mathrm{Ru}$ / Ni8Ru5Re and (b) Ni8Ru/Ni8Ru5W pseudo-binary diffusion couples annealed at $1523 \mathrm{~K}$ for $259.2 \mathrm{ks}$ showing uphill diffusion phenomena in both systems.

altered by the diffusion of Co but the reverse situation is not noted. From this result, it is clear that, Co seems to have more appreciable effect than $\mathrm{Ru}$ with respect to chemical activity of Re, which indicates that the thermodynamic interaction of $\mathrm{Co}-\mathrm{Re}$ in Ni may be larger than that of Ru-Re.

The redistribution profile of uphill diffusion can reflect qualitatively the degree and the sign of the cross interdiffusion coefficient. In the pseudo-binary systems, as mentioned above, the flux of uphill diffusion is governed only by the second term of eq. (1) because the first term in the equation is zero due to constant concentration. In Fig. 3(a) and (b), as $\mathrm{Ru}$ shows clearly uphill diffusion under the influence of $\mathrm{Re}$ and $\mathrm{W}$, respectively, both cross interdiffusion coefficients $\tilde{D}_{\mathrm{RuRe}}^{\mathrm{Ni}}$ and $\tilde{D}_{\mathrm{RuW}}^{\mathrm{Ni}}$ should not be equal to zero and have a certain value such that contributing to the interdiffusion flux of $\mathrm{Ru}$. For the sign of the cross interdiffusion coefficient, it is determined by the location of the maximum concentration of the profile because it reflects the direction of the diffusion. From Fig. 3(a) and (b), the maximum concentration of $\mathrm{Ru}$ is located in the Re-rich area and W-rich area indicating that $\mathrm{Ru}$ diffuses up the concentration gradients of both Re and W. Therefore, both $\tilde{D}_{\mathrm{RuRe}}^{\mathrm{Ni}}$ and $\tilde{D}_{\mathrm{RuW}}^{\mathrm{Ni}}$ should have negative signs. On the other hand, because Re does not show clearly the uphill diffusion in Ni-Ru-Re pseudo-binary system as 

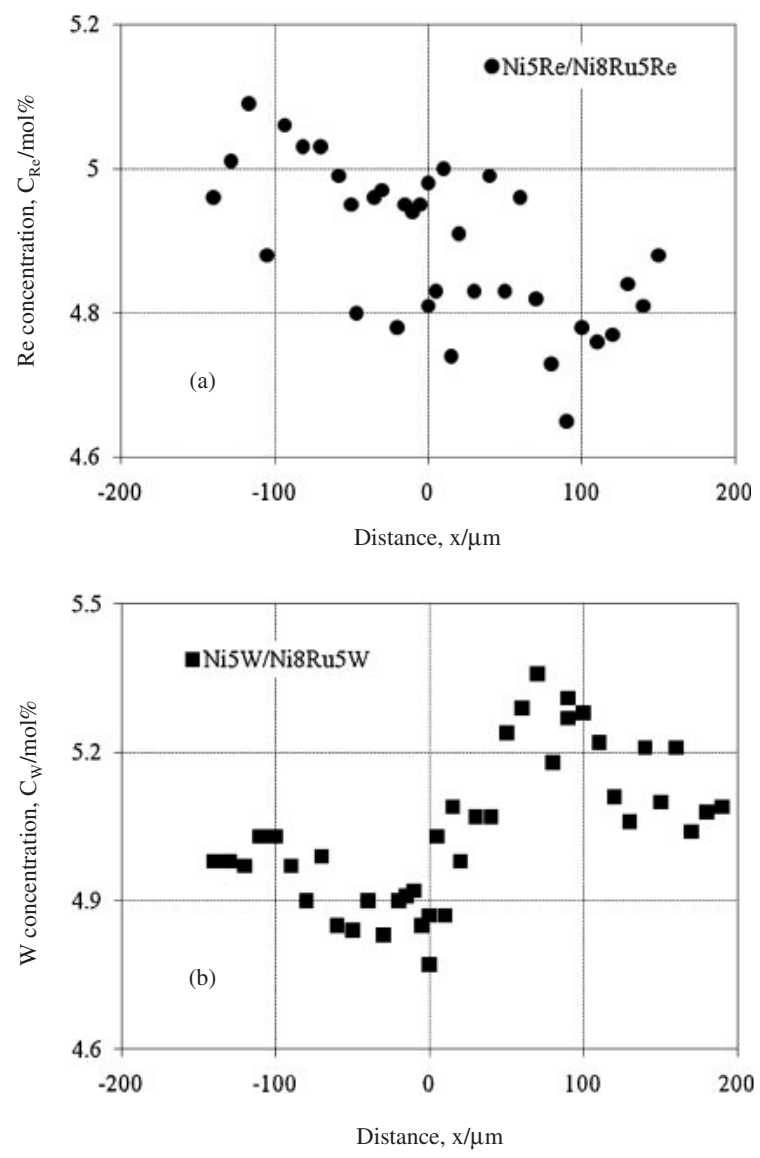

Fig. 4 Enlarged views of the redistribution profiles of $\mathrm{Re}$ and $\mathrm{W}$ in the pseudo-binary diffusion couples of (a) Ni5Re/Ni8Ru5Re and (b) Ni5W/ Ni8Ru5W, respectively, after annealing at $1523 \mathrm{~K}$ for $259.2 \mathrm{ks}$. The uphill diffusion phenomena is clearly observed only for $\mathrm{W}$.

illustrated in Fig. 4(a), $\tilde{D}_{\mathrm{ReRu}}^{\mathrm{Ni}}$ should be nearly zero. With respect to $\tilde{D}_{\mathrm{WRu}}^{\mathrm{Ni}}$, by analyzing the $\mathrm{W}$ uphill diffusion profile in Fig. 4(b), $\tilde{D}_{\mathrm{WRu}}^{\mathrm{Ni}}$ should have a negative certain value (not be zero). The similar analysis is applied to the pseudo-binary diffusion couples of Ni-Co-Re system shown in Fig. 5(a) and (b) and the result shows that $\tilde{D}_{\mathrm{ReCo}}^{\mathrm{Ni}}$ is negative and has a certain value where $\tilde{D}_{\mathrm{CoRe}}^{\mathrm{Ni}}$ is negligibly zero. The results of the cross interdiffusion coefficients in this study are in reasonable agreement with the ones reported by Hattori et al. ${ }^{20)}$ for $\mathrm{Ni}-\mathrm{Ru}-\mathrm{Re}$ and $\mathrm{Ni}-\mathrm{Ru}-\mathrm{W}$ systems and by Mabruri et al. for $\mathrm{Ni}-\mathrm{Co}-\mathrm{Re}$ system. ${ }^{22)}$

Figure 6(a) and (b) illustrates comparison of the redistribution profiles in the binary and the pseudo-binary systems of the main diffusing elements of Re and $\mathrm{W}$ in $\mathrm{Ni}-\mathrm{Ru}-\mathrm{Re}$ and $\mathrm{Ni}-\mathrm{Ru}-\mathrm{W}$ systems, respectively. It is shown that the profiles of both elements in the pseudo-binary systems have slightly shorter diffusion distances. This means that the presence of Ru may slightly affect the diffusion of $\mathrm{Re}$ and $\mathrm{W}$. In order to compare the diffusion profiles of $\mathrm{Ru}$, the normalized concentration is employed to avoid the difference in the initial concentration of $\mathrm{Ru}$ between the binary couple $(5 \mathrm{~mol} \%)$ and the pseudo-binary couples $(8 \mathrm{~mol} \%)$. The normalized concentration gradient is defined by $Y_{i}=\left(C_{i}-C_{i}^{-}\right) /\left(C_{i}^{+}-C_{i}^{-}\right)$, where $C_{i}$ is the measured concentration of element $i, C_{i}^{-}$and $C_{i}^{+}$are the terminal concentrations of element $i$ at the distance of $-\infty$ and $+\infty$,
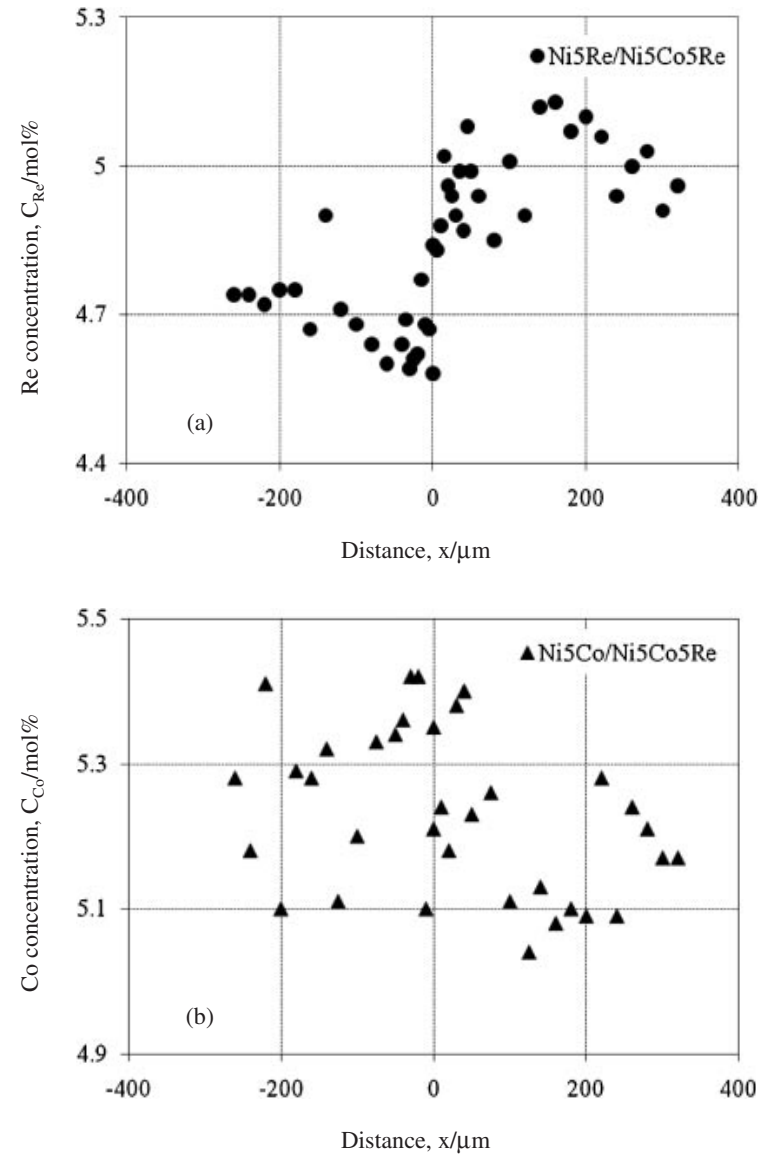

Fig. 5 Enlarged views of the redistribution profiles of $\mathrm{Co}$ and $\mathrm{Re}$ in the pseudo-binary diffusion couples of (a) Ni5Re/Ni5Co5Re and (b) Ni5Co/ Ni5Co5Re, respectively, after annealing at $1523 \mathrm{~K}$ for $259.2 \mathrm{ks}$. The uphill diffusion phenomena is clearly observed for Re but not for Co.

respectively. Figure 7 displays the comparison of the normalized concentration profiles of $\mathrm{Ru}$ in the binary couple $\mathrm{Ni} / \mathrm{Ni5Ru}$ and in the pseudo-binary couples of $\mathrm{Ni} 5 \mathrm{Re} /$ $\mathrm{Ni} 8 \mathrm{Ru} 5 \mathrm{Re}$ and Ni5W/Ni8Ru5W. It is clear that Ru diffuses in a shorter distance in both pseudo-binaries Ni-Ru-Re and $\mathrm{Ni}-\mathrm{Ru}-\mathrm{W}$ than in the binary $\mathrm{Ni}-\mathrm{Ru}$, which means that both $\mathrm{Re}$ and $\mathrm{W}$ reduce the diffusivity of $\mathrm{Ru}$ in the respective pseudo-binary system.

The results in Fig. 6 and 7 can be clarified by the estimation of the interdiffusion coefficients of elements in their respective diffusion couples. Since one of the solute concentration in the pseudo-binary diffusion couples is assumed to be a constant along the diffusion zone, the interdiffusion coefficient of the diffusing solute can be determined by the Sauer and Freise method applicable for the binary system ${ }^{24)}$ using the following equation:

$$
\begin{aligned}
\tilde{D}= & (1 / 2 t)\left(d x / d Y_{i}\right) \\
& \times\left[\left(1-Y_{i}\right) \int_{-\infty}^{x} Y_{i} d x+Y_{i} \int_{x}^{+\infty}\left(1-Y_{i}\right) d x\right],
\end{aligned}
$$

where $Y_{i}$ is the normalized concentration defined in the previous paragraph, $t$ and $x$ are diffusion time and distance, respectively. The calculation of interdiffusion coefficient is carried out on the fitted redistribution profiles represented by the following equation: 

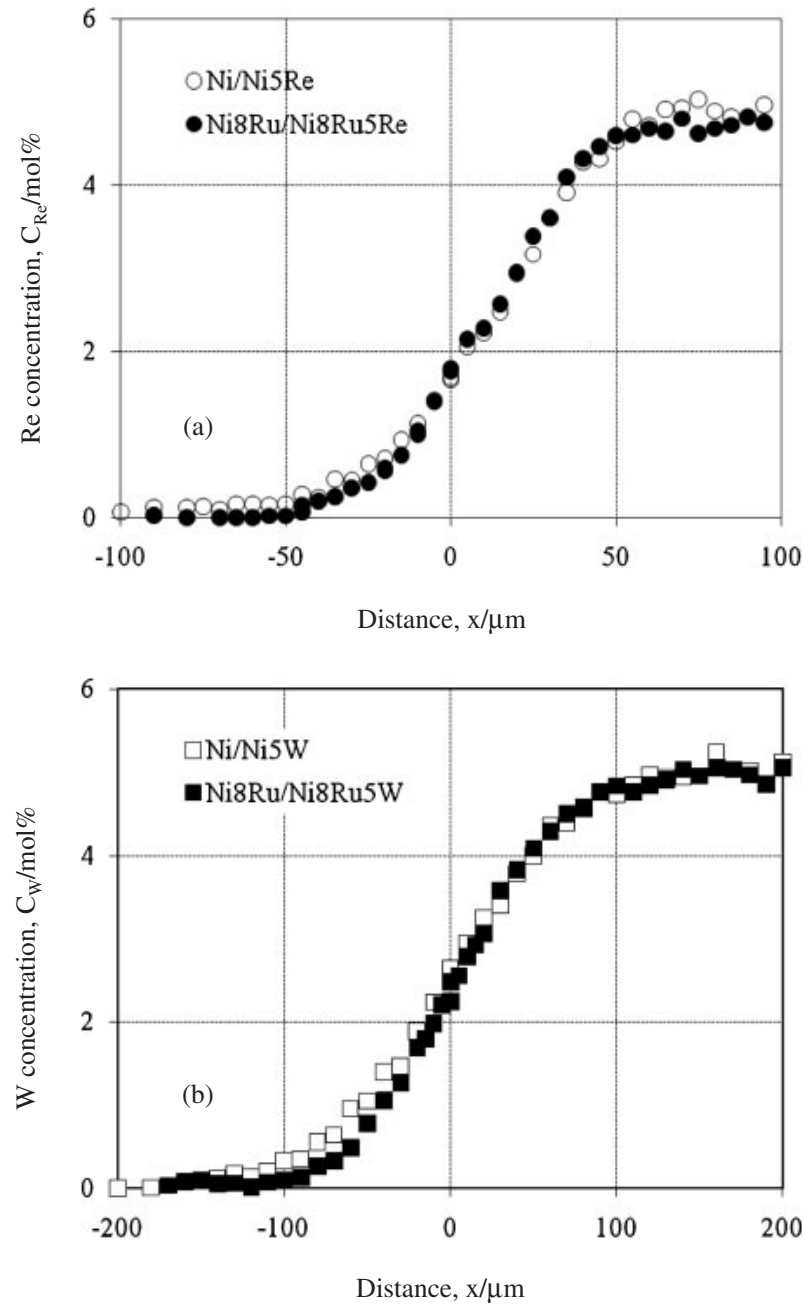

Fig. 6 Comparison of the redistribution profiles of (a) Re and (b) W between their respective binary and the pseudo-binary diffusion couples after annealing at $1523 \mathrm{~K}$ for $259.2 \mathrm{ks}$.

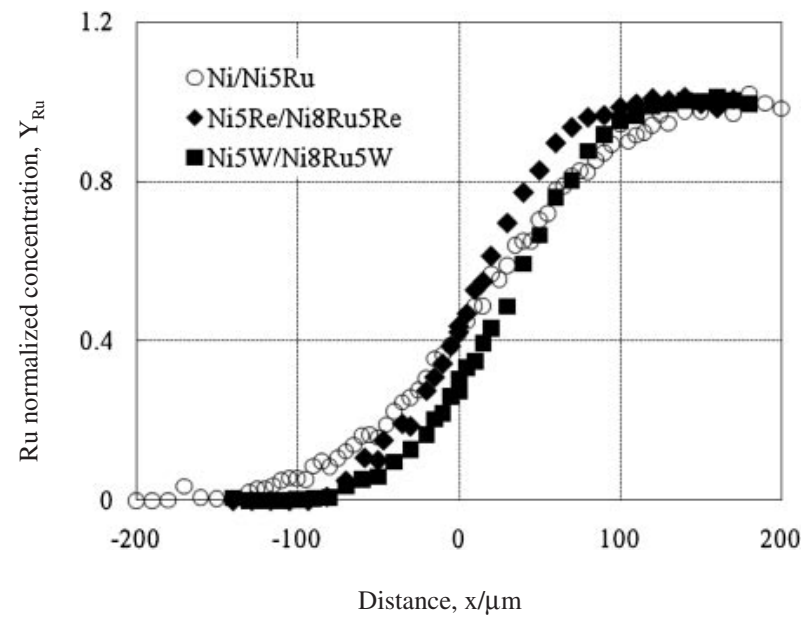

Fig. 7 Comparison of the normalized concentration profiles of Ru between the binary and the pseudo-binary diffusion couples annealed at $1523 \mathrm{~K}$ for $259.2 \mathrm{ks}$.

$$
C_{i}(x)=C_{i}^{-}+\frac{C_{i}^{+}-C_{i}^{-}}{2}[1+\operatorname{erf}(f x)]
$$

where $f x$ is the polynomial function upon $x$.

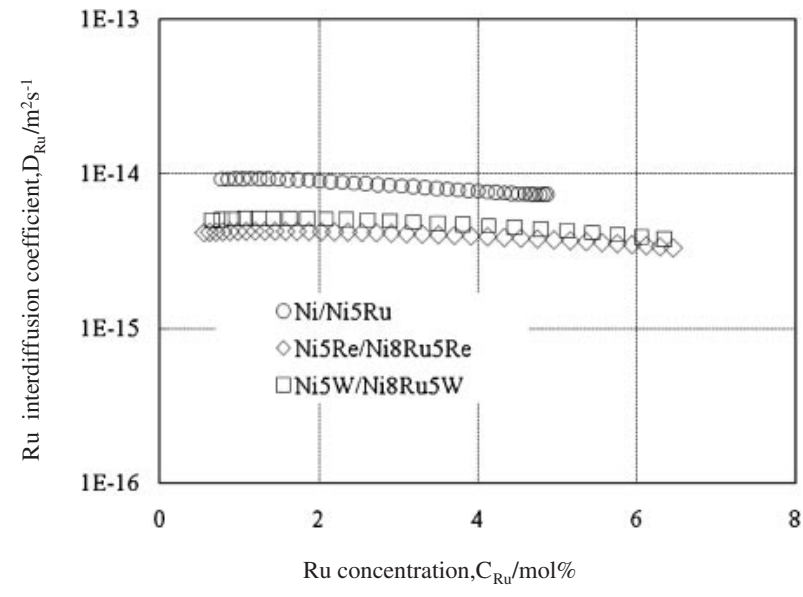

Fig. 8 The Interdiffusion coefficients of Ru in the binary and pseudobinary diffusion couples annealed at $1523 \mathrm{~K}$ for $259.2 \mathrm{ks}$.

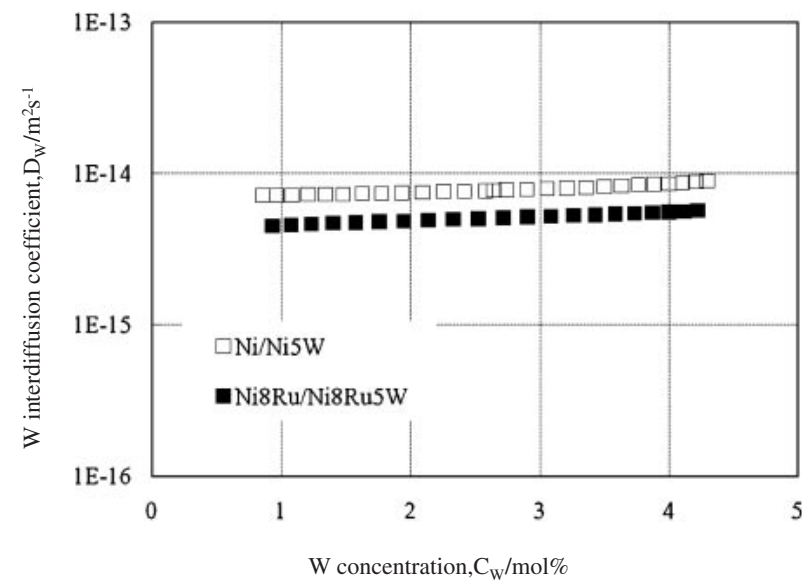

Fig. 9 The Interdiffusion coefficients of $\mathrm{W}$ in the binary and pseudo-binary diffusion couples annealed at $1523 \mathrm{~K}$ for $259.2 \mathrm{ks}$.

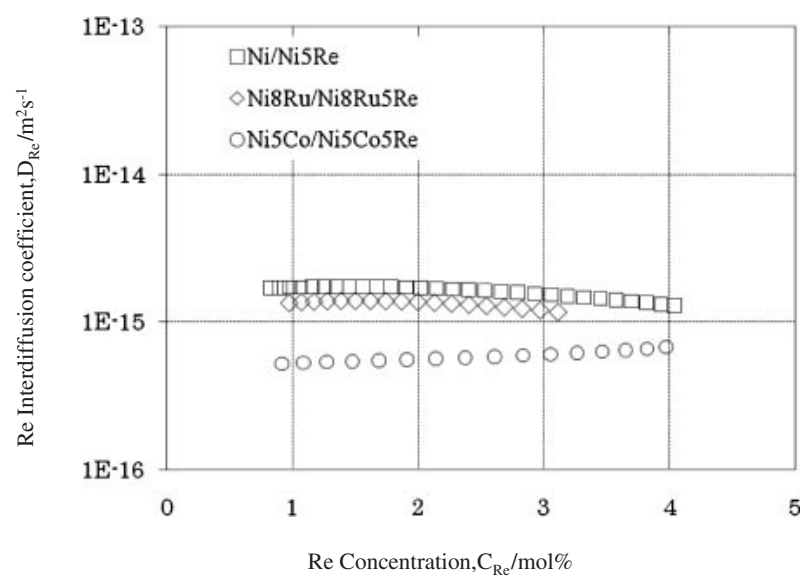

Fig. 10 The Interdiffusion coefficients of Re in the binary and pseudobinary diffusion couples annealed at $1523 \mathrm{~K}$ for $259.2 \mathrm{ks}$.

Figures 8-10 present the interdiffusion coefficients of $\mathrm{Ru}$, $\mathrm{W}$ and Re in the binary and pseudo-binary diffusion couples plotted against the concentration of $\mathrm{Ru}, \mathrm{W}$ and $\mathrm{Re}$, respectively. It can be seen from Fig. 8 that the interdiffusion coefficient of $\mathrm{Ru}$ is lower in both pseudo-binary couples of 
$\mathrm{Ni5Re} / \mathrm{Ni} 8 \mathrm{Ru} 5 \mathrm{Re}$ and Ni5W/Ni8Ru5W than in the binary couple $\mathrm{Ni} / \mathrm{Ni} 5 \mathrm{Ru}$. The effect of the presence of Ru atoms on W diffusivity appears in Fig. 9 which shows that modest reduction in the interdiffusion coefficient of $\mathrm{W}$ is observed in the pseudo-binary couple of Ni8Ru/Ni8Ru5W when compared to that in the binary couple of Ni/Ni5W. As for Re, by comparing the interdiffusion coefficients in the binary and the pseudo-binary diffusion couples revealed in Fig. 10, it is shown that the diffusivity of Re only slightly decreases in the presence of $\mathrm{Ru}$ in the couple of Ni8Ru/Ni8Ru5Re but large reduction is observed in the presence of Co in the couple of $\mathrm{Ni5Co/Ni5Co5Re.} \mathrm{This} \mathrm{means} \mathrm{that} \mathrm{Co} \mathrm{is} \mathrm{more} \mathrm{powerful}$ barrier atoms than $\mathrm{Ru}$ to decrease the diffusivity of Re in nickel alloys. It can be deduced from this fact that the interatomic bonding of Co-Re may be stronger than that of Ru-Re giving that the larger resisting effect are provided by Co atoms against the migration of $\mathrm{Re}$ atoms in $\mathrm{Ni}$ alloys. This result also may be explained by the fact that $\mathrm{Co}$ and $\mathrm{Ni}$ have a large solid solubility in one another, ${ }^{25)}$ so that the incorporation of $\mathrm{Co}$ into $\mathrm{Ni}$ alloys will reduce the vacancy concentration resulting in the decreasing of the probability for Re atoms to have a vacant nearest-neighbor site which, eventually reduces the interdiffusion rate.

\section{2 $\gamma^{\prime}$ phase coarsening kinetics in model superalloys}

It is well known that the diffusion of the elements in the matrix of $\gamma$ phase is the main factor influencing the transport of the elements across the interface of matrix-precipitate during coarsening of the $\gamma^{\prime}$ phase and the TCP phases as well at high temperature in nickel based superalloys. It has been reported by A. F. Giamei et al. ${ }^{8)}$ that Re substitution for W in a typical nickel based superalloy substantially reduced the coarsening rate of the $\gamma^{\prime}$ phase and the rate constant was found to be diffusion controlled with a one-third time exponent functionality. It is deduced from this result that Re is believed as the rate-controlling element in the coarsening of the $\gamma^{\prime}$ phase. Therefore, influencing the diffusion rate of Re in nickel based superalloys may result in the modification of the $\gamma^{\prime}$ phase coarsening rate. As Co reduces the diffusivity of Re in large extent as shown in the previous section, the presence of Co may decrease the coarsening rate of the $\gamma^{\prime}$ phase. Reduction of the $\gamma^{\prime}$ phase coarsening rate by increasing Co content has been documented in literature for Re-free W-containing superalloys. ${ }^{26)}$ With respect to $\mathrm{Ru}$, which only changes slightly the diffusivity of Re as shown in the previous section, the effect of Ru addition on the coarsening of $\gamma^{\prime}$ phase may be insignificantly notable.

In order to ensure the above hypothesis of Ru effect, the $\gamma^{\prime}$ phase coarsening at $1324 \mathrm{~K}$ is investigated using two model superalloys. The compositions of the two model superalloys are designed in the vicinity of the composition of the third generation single crystal superalloys and they are different in Ru content of 0 and $4 \mathrm{~mol} \%$ and are roughly similar in the composition of other elements as shown in Table 2. For checking the applicability of Lifshitz, Slyozov and Wagner (LSW) theory for the diffusion controlled coarsening process, ${ }^{27,28)}$ the average sizes of $\gamma^{\prime}$ are plotted as a function of $t^{1 / 3}$. The average length of $\gamma^{\prime}$ cube-edges, $\bar{a} / 2$ is used instead of $\bar{r}$ of particle radius because both model superalloys reveal the cuboidal $\gamma^{\prime}$ microstructure after aging heat

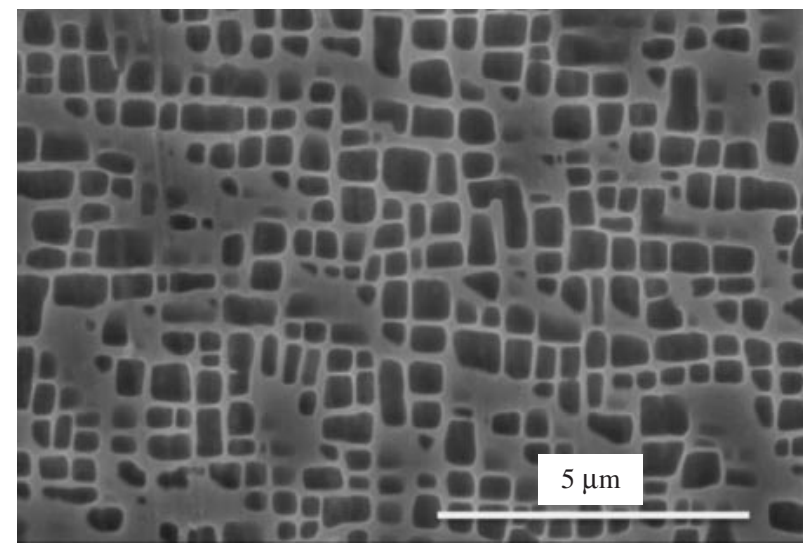

(a)

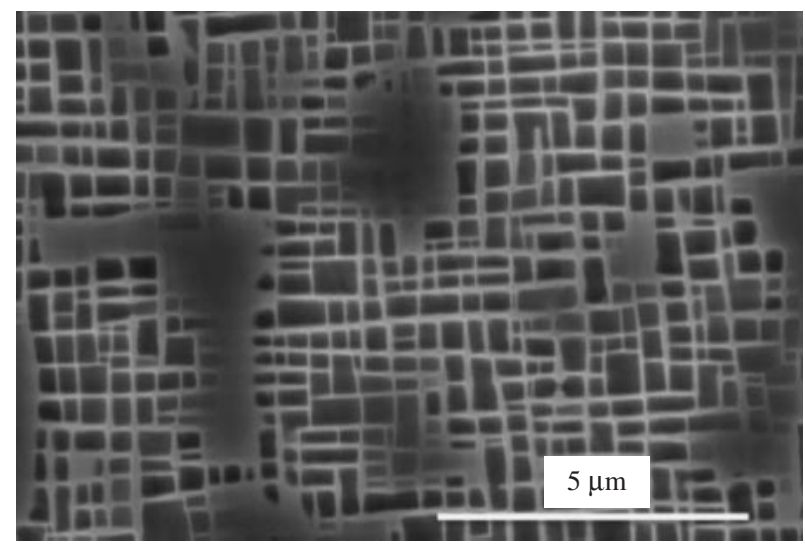

(b)

Fig. 11 Typical microstructures for (a) Ru-free and (b) 4 mol\%Ru model superalloys aged at $1324 \mathrm{~K}$ for $72 \mathrm{~h}$.

treatment. Typical microstructures of the two alloys aged at $1324 \mathrm{~K}$ for $72 \mathrm{~h}$ are shown in Fig. 11(a) and (b).

The LSW theory for coarsening kinetics is then represented by the following equation:

$$
\left(\frac{\bar{a}}{2}\right)-\left(\frac{\bar{a}_{0}}{2}\right)=k t^{1 / 3}
$$

where $\bar{a}_{0} / 2$ denotes the average length of $\gamma^{\prime}$ cube-edges at the onset of coarsening, $k$ and $t$ denote the coarsening rate constant and the time, respectively. The rate constant $k$ is defined by the following equation:

$$
k=\frac{8 \sigma D C_{e} V_{m}^{2}}{9 R T},
$$

where $\sigma$ is the matrix-precipitate interfacial energy, $D$ is the volume diffusion coefficient of the solute in the matrix, $C_{e}$ is the solute equilibrium concentration of the matrix, $V_{m}$ is the molar volume of the precipitate, $R$ is the universal gas constant and $T$ is the absolute temperature. Although the representation of the rate constant $k$ has been modified to account the precipitate volume fraction effect which suitable for superalloys as for example, conducted by Brailsford and Winblat ${ }^{29)}$ and Davies et al. ${ }^{30)}$ the use of the original one is sufficient for the analysis of $\gamma^{\prime}$ coarsening in this study since the coalescence of the $\gamma^{\prime}$ precipitates is not evident for the two model superalloys over the aging times applied. If any, it 


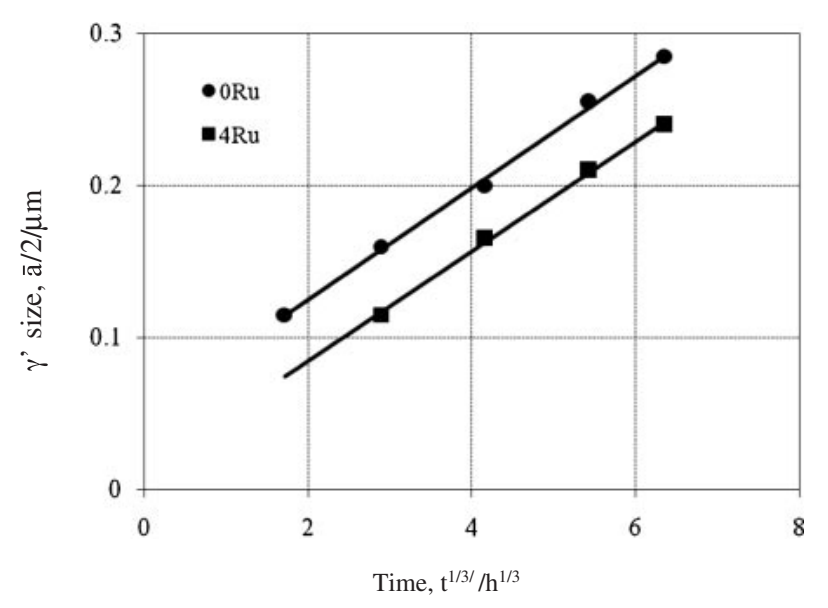

Fig. 12 Plot of average length of $\gamma^{\prime}$ cube-edges versus time ${ }^{1 / 3}$ for two model superalloys aged at $1324 \mathrm{~K}$.

is in negligibly small fraction and is not the predominant mechanism. However, from this extended theory it is noted that for the multicomponent alloys such as superalloys, $D$ and $C_{e}$ appearing in eq. (5) are accounted for the rate controlling solute element.

Figure 12 presents the plot of $\bar{a} / 2$ as a function of $t^{1 / 3}$ for aging temperature of $1324 \mathrm{~K}$. It is shown that the data points of $\bar{a} / 2$ for the two model superalloys fit linearly with $t^{1 / 3}$. This indicates that the coarsening of $\gamma^{\prime}$ phase in both alloys is a diffusion controlled process. The slope of the linear fits corresponds to the coarsening rate constant $k$ and, is found to be exactly similar for both alloys, i.e. $0.036 \mu \mathrm{m} / \mathrm{h}^{1 / 3}$. This gives the conclusion that the addition of $\mathrm{Ru}$ does not change the $\gamma^{\prime}$ phase coarsening rate of the superalloy. The presence of $\mathrm{Ru}$ may change the parameters revealed in eq. (5), but the changes appear to balance each other resulting in the unchanged rate constant. Considering that the $\gamma^{\prime}$ sizes are slightly lower for the Ru-containing superalloy compared to the Ru-free superalloy over the aging times concerned in this study as shown in Fig. 12, a little increase in the interfacial energy $(\sigma)$ is expected from the addition of Ru into the alloy. However, by assuming that the parameters of $V_{m}$ and $C_{e}$ appearing in eq. (5) are constant the increasing in the interfacial energy may be balanced with the slightly decreasing of the diffusivity of the rate-controlling element $\mathrm{Re}$ in the presence of $\mathrm{Ru}$. This is consistent with the result shown in the previous section that Ru reduced slightly the diffusivity of Re.

The low diffusivity of refractory elements is one of the important roles in enhancing the high temperature creep strength of the nickel based superalloys. The result of this work shows that the addition of Ru to the nickel based alloys changes only slightly the diffusivity of Re and modestly that of W. It is also shown that Ru scarcely changes the diffusioncontrolled coarsening kinetics of the $\gamma^{\prime}$ phase. This suggests that the increasing of the creep strength by $\mathrm{Ru}$ addition may not appear to be due to changing diffusion kinetics. Here, it is known that $\mathrm{Co}$ is a similar element to $\mathrm{Ru}$ with respect to the improvement of the phase stability of the nickel based superalloys. ${ }^{17)}$ But Co decreased the diffusivity, especially for Re in large extent ${ }^{22)}$ and lowered the $\gamma^{\prime}$ phase coarsening rate $^{26)}$ resulting in the enhanced creep performance. ${ }^{17,18,31)}$ Furthermore, this work shows that there is a decrease in the chemical activity of the elements caused by the $\mathrm{Ru}-\mathrm{Re}, \mathrm{Ru}-\mathrm{W}$ and Co-Re interactions as shown by the occurrence of the uphill diffusion in the previous section. This is an indication of the thermodynamically stable Ru-Re, $\mathrm{Ru}-\mathrm{W}$ and Co-Re bonds which may contribute to the improvement of the creep strength of the advanced nickel based superalloys. ${ }^{32)}$

\section{Conclusion}

The interdiffusion of Re, $\mathrm{W}, \mathrm{Ru}$ and $\mathrm{Co}$ in the binary and pseudo-binary Ni based alloys at $1523 \mathrm{~K}$ and the $\gamma^{\prime}$ phase coarsening kinetics of model superalloys at $1324 \mathrm{~K}$ have been investigated. The experimental results showed that both $\mathrm{Re}$ and $\mathrm{W}$ concentration gradients caused $\mathrm{Ru}$ uphill diffusion in the respective pseudo-binary diffusion couple. On the other hand, $\mathrm{Ru}$ concentration gradient promoted uphill diffusion for $\mathrm{W}$ but not for Re. Interestingly, Re uphill diffusion occurred under the influence of Co concentration gradient but Co uphill diffusion was not observed in the presence of Re concentration gradient. The cross interdiffusion coefficients qualitatively determined from the uphill diffusion profiles were in reasonable agreement with those reported previously. By comparing the interdiffusion coefficients in the binary and the pseudo-binary diffusion couples, it was found that Ru and W decreased the diffusivity of each other whereas Co has a stronger effect than $\mathrm{Ru}$ on decreasing the Re diffusivity. Furthermore, it was found that the coarsening kinetics of the $\gamma^{\prime}$ phase in both Ru-free and Ru-containing model superalloys were controlled by diffusion and Ru did not have any effect on the rate constant of the $\gamma^{\prime}$ phase coarsening.

\section{Acknowledgements}

This work was supported in part by Grant-in-Aid for Scientific Research of Japan Society for the Promotion of Science (JSPS), Japan.

\section{REFERENCES}

1) P. Carron and T. Khan: Aerosp. Sci. Technol. 3 (1999) 513-523.

2) K. Matsugi, Y. Murata, M. Morinaga and N. Yukawa: Superalloys 1992, (TMS, Warrendale, PA) pp. 307-316.

3) T. Hino, et al.: Materials for Adv. Power Eng. 1998, (Forschungszentrum Julich Publisher, Julich) pp. 1129.

4) R. Darolia, D. F. Lahrman and R. D. Field: Superalloys 1998, (TMS, Warrendale, PA) pp. 255-264.

5) D. Blavette, P. Caron and T. Khan: Scripta Metall. 20 (1986) 13951400 .

6) N. Wanderka and U. Glatzel: Mater. Sci. Eng. A203 (1995) 69-.

7) A. F. Giamei and D. L. Anton: Met. Trans. A16 (1985) 1997-2005.

8) M. S. A. Karunaratne, P. Carter and R. C. Reed: Mater. Sci. and Eng. A281 (2000) 229-233.

9) G. L. Errickson: Superalloys 1996, (TMS, Warrendale, PA) pp. 35-44.

10) R. M. Kearsey, J. C. Beddoes, P. Jones and P. Au: Intermetallic 12 (2004) 903-910.

11) C. M. F. Rae and R. C. Reed: Acta Mater. 49 (2001) 4113-4125.

12) P. Caron: Superalloys 2000, (TMS, Warrendale, PA) pp. 737-746.

13) A. Sato et al.: Scripta Mater. 54 (2006) 1679-1684.

14) Y. Koizumi, T. Kobayashi, T. Yokokawa, Z. Jianxin, M. Osawa, 
H. Harada, Y. Aoki and M. Arai: Superalloys 2004, (TMS, Warrendale, PA) pp. $35-43$.

15) F. Pyczak, B. Devrient, F. C. Neune and H. Mughrabi: Acta Mater. 53 (2005) 3879-3891.

16) A. C. Yeh and S. Tin: Scripta Mater. 52 (2005) 519-524.

17) S. Walston, A. Cetel, R. Mackay, K. Ohara, D. Duhl and R. Dreshfield: Superalloys 2004, (TMS, Warrendale, PA) pp. 15-24.

18) L. J. Rowland, Q. Feng and T. M. Pollock: Superalloys 2004, (TMS, Warrendale, PA) pp. 697-706

19) M. Hattori, N. Goto, Y. Murata, T. Koyama and M. Morinaga: Mater. Trans. 46 (2005) 163-166.

20) M. Hattori, N. Goto, Y. Murata, T. Koyama and M. Morinaga: Mater. Trans. 47 (2006) 331-334.

21) E. Mabruri, M. Hattori, K. Hasuike, T. Kunieda, Y. Murata and M. Morinaga: Mater. Trans. 47 (2006) 1408-1411.

22) E. Mabruri, S. Sakurai, Y. Murata, T. Koyama and M. Morinaga:
Mater. Trans. 48 (2007) 2718-2723.

23) UHTSCA ImageTool software, available online at http://ddsdx. uthscsa.edu/dig/itdesc.html.

24) F. Sauer and V. Freise: Z. Elektrochem. 66 (1962) 353-363.

$25)$ T. B. Massalski: Binary Alloys Phase Diagram, 2nd Edition, (ASM International, Materials Park, OH) 1990.

26) M. V. Nathal and L. J. Ebert: Metall. Trans. 16 A (1985) 1849-1862.

27) I. Lifshitz and V. Slyozov: J. Phys. Chem. Sol. 19 (1961) 35.

28) C. Wagner: Elektrochem. 65 (1961) 581.

29) A. D. Brailsford and P. Wynblatt: Acta Metall. 27 (1979) $489-497$.

30) C. K. L. Davies, P. Nash and R. N. Steves: Acta Metall. 28 (1980) 179-189.

31) Y. Murata, R. Hashizume, A. Yoshinari, N. Naoki, M. Morinaga and Y. Fukui: Superalloys 2000, (TMS, Warrendale, PA) pp. 285-294.

32) R. A. Hobbs, M. S. A. Karunaratne, S. Tin, R. C. Reed and C. M. F. Rae: Mater. Sci. Eng., A 460-461 (2007) 587-594. 